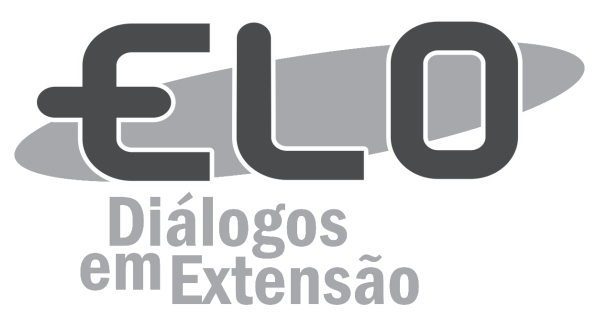

\title{
Agroecologia urbana: ensino, pesquisa e extensão na escola
}

\author{
Cristiane Rocha Silva ${ }^{1}$,Roseli de Fátima dos Santos de Almeida², Márcia Marzagão
}

\begin{abstract}
Resumo: A equipe do projeto de extensão "Agroecologia Urbana" relata a experiência de ações vinculadas ao ensino curricular do módulo "Interações Culturais Humanísticas - Agroecologia na escola" ofertado no primeiro e no segundo semestre de 2014. As práticas extensionistas, em parceria com escolas municipais e estaduais de ensino, potencializaram atividades de pesquisa, interação social e planejamento dos estudantes da Universidade Federal do Paraná, setor Litoral, e dos estudantes das escolas parceiras, no âmbito do projeto de extensão. A metodologia dialógica e participativa, com envolvimento dos partícipes no planejamento, execução e avaliação, bem como a predisposição a ações coletivas foram fundamentais para realização das atividades $e$ do objetivo comum. Objetivo esse de sensibilização das questões ambientais e do potencial de práticas de produção e consumo agroecológicos no cotidiano urbano.
\end{abstract}

Palavras-chave: Projeto interinstitucional. Meio ambiente. Interdisciplinaridade.

Área Temática: Agroecologia. Educação.

\section{Urban agroecology: teaching, research and extension in school}

Abstract: The extension project team "Agroecology Urban " reports the experience of actions related to the curriculum teaching module Humanistic Cultural Interactions - "Agroecology in school "offered in the first and second semester of 2014. The extension practices in partnership with municipal and state schools teaching potentiated research activities, social interaction and planning of students of the Federal University of Parana, Coastline sector and students of partner schools under the extension project. The dialogic and participatory approach with the involvement of the participants in the planning, implementation and evaluation, as well as predisposition to collective actions were instrumental in carrying out the activities and the common goal. This objective awareness of environmental issues and the potential for production of agroecological practices and consumption in urban daily life.

Keywords: Institutional project. Environment. Interdisciplinarity.

\section{Agroecologia urbana : la enseñanza, la investigación y la extensión en la escuela}

Resumen: El equipo del proyecto de extensión "Agroecología Urbana ", informa la experiencia de las acciones relacionadas con el plan de estudios de la enseñanza em las classes de Interacciones Culturales Humanísticas - "Agroecología en la escuela " que se ofrece en la primera y la segunda mitad de 2014. Las prácticas de extensión en colaboración con la enseñanza de las escuelas municipales y e regionales que potenciaban las actividades de investigación, la interacción social y la planificación de los estudiantes de la Universidad Federal de Paraná, sector Litoral y alumnos de las escuelas

\footnotetext{
${ }^{1}$ Universidade Federal do Paraná - Setor litoral - coordenadora do projeto de extensão Agroecologia urbana -2014-2015 _ Rua São Mateus, 1253 - Matinhos - PR - 55(11)959219902 - Brasil - cris.

${ }^{2}$ Secretaria Municipal de Educação de Matinhos - Diretora do CMEI Caminho Alegre- 2013-2016- Rua Cornélio Procópio s/nº Matinhos- PR - rose-.-lee@hotmail.com - Brasil.

${ }^{3}$ Universidade Federal do Paraná - Setor Ciências Agrárias - vice-coordenadora do projeto Agroecologia Urbana 2014-2015 - 55(41)9607-0393- marzagao@ufpr.br - Brasil.
} 
asociadas al proyecto. El enfoque dialógico y participativo con la implicación de los participantes en la planificación, ejecución y evaluación, así como la predisposición a las acciones colectivas tuvieron un papel decisivo en la realización de las actividades y el objetivo común. El objetivo de reflexionar sobre las cuestiones ambientales y el potencial de producción de prácticas agroecológicas y el consumo en la vida cotidiana en la ciudad.

Palabras clave: Proyecto institucional. Medio ambiente. La interdisciplinariedad

\section{Introdução}

O presente texto relata as articulações do projeto de extensão "Agroecologia Urbana" da UFPR e o projeto escolar "Meio Ambiente, Escola e Família" do Centro Municipal de Educação Infantil Caminho Alegre (CMEI), localizado no estado do Paraná, que desencadearam uma proposta curricular no ensino de graduação da Universidade Federal do Paraná (UFPR), setor litoral, sob o título "Agroecologia na Escola". Seguindo essa proposta, foram realizadas atividades de pesquisa e intervenção em quatro instituições de ensino do município de Matinhos e envolveram, no primeiro semestre de 2015, cerca de 255 crianças do ensino infantil e fundamental e 19 estudantes de graduação.

O espaço de interações culturais e humanísticas - ICH, previsto no projeto político pedagógico do setor litoral, tem uma ementa flexível e pertinente às demandas de articulação em pesquisa e extensão, o que favoreceu a organização do grupo, a inscrição dos estudantes de graduação de acordo com o interesse pela temática, o planejamento coletivo dos objetivos de aprendizagem e a intervenção nas escolas.

O mesmo processo dialógico de construção das atividades de organização do módulo foi enfatizado na articulação das atividades nas escolas e abordou a necessidade de estabelecimento de vínculos de confiança e respeito às atividades e projetos já realizados nas instituições de ensino, além do planejamento coletivo a partir das demandas e potencialidades da própria escola, em acordo com o planejamento escolar e projeto político pedagógico em estreito diálogo com a direção, coordenação e educadoras. Enfatizou-se, ainda, o estabelecimento de ciclos de duração máxima de 4 meses, com um planejamento de início, finalização e avaliação com educadores, coordenação e direção das ações realizadas.

Salienta-se que a abordagem de temas relacionados ao ambiente, à consciência ambiental e aos mecanismos de observação concreta e sensorial dos fenômenos naturais e sociais estão alinhados com as diretrizes curriculares da educação infantil da legislação brasileira e educadores ambientais (BRASIL, 1996; 1998; 2010a; 2010b; LIBANEO; 2.009).

\section{Metodologia}

Foram desenvolvidas ações de intervenção nas seguintes instituições:

a) Escola Estadual Teresa Ramos - dinâmicas de jogos e interação com sementes, reconhecimento da natureza e interação coletiva com o grupo "Mais Educação", no período da manhã. (40 crianças)

b) Centro Municipal de Educação Infantil Caminho Alegre - revitalização de espaços pedagógicos e ornamentais. (80 crianças)

c) Escola Municipal Quatro de Março - Ação pedagógica com o primeiro ano, sobre árvores nativas (pitanga) e alimentação, estabelecendo relações com a natureza. (15 crianças)

d) Escola Municipal Caetana Paranhos - Revitalização do canteiro e espaços associados; exposição de temas relacionados ao livro didático (fases da lua, fotossíntese, terra, água) e agroecologia -. Quatro turmas da manhã de quarto e quinto ano. (120 crianças)

A comunicação entre as ações dos grupos, educadores, pais e funcionários da secretaria de educação contou com uma ferramenta adicional, a criação de um grupo nas redes sociais que reuniu, durante o primeiro semestre de 2015, imagens, relatos, avaliações, ementas, planos de trabalho, vídeos, textos e outras experiências relacionadas a temática da agroecologia na escola. O grupo foi organizado na plataforma facebook com o título "Agroecologia nas escolas".

Observou-se que a ação concreta de articulação, o contato com os atores envolvidos e a flexibilidade dos temas exigiu dos estudantes a pesquisa de diferentes temáticas para o preparo das atividades, bem como o manuseio de ferramentas, vocabulário, metodologias didáticas e recursos naturais o que 
possibilitou uma experiência enriquecedora para as crianças, estudantes e educadores. Por outro lado, a avaliação dos educadores, coordenação e direção demonstrou que a articulação universidade/escola potencializou as atividades da instituição e promoveu o seu envolvimento com as temáticas ligadas a agroecologia.

Em um momento de depredação dos recursos naturais a fim de obter um padrão de vida consumista e um crescimento industrial, torna-se cada vez mais necessário incluir as temáticas de conservação do meio ambiente e repensar práticas de convivência urbana.

Nesse sentido, entende-se que a agroecologia na escola tem um papel fundamental de provocar rupturas de pensamento, ampliar o olhar sobre nosso ambiente, sobre as relações estabelecidas, as formas de produção e consumo e as nossas escolhas cotidianas.

O impacto na formação dos estudantes se deu nos campos do ensino, da pesquisa e da extensão no seu aspecto indissociável, visto que a ação de intervenção funcionou como um campo gerador, demandando a pesquisa de temas, metodologias e interações com diferentes atores, o que fomentou e ampliou as discussões, debates e momentos de formação em sala de aula.

\section{Resultados e Discussões}

A partir dos relatos escritos de 17 estudantes de graduação matriculados no módulo ICH, coletados nos dias 10 e 17 de junho de 2015, semana de finalização das atividades, foi possível identificar apreensões no envolvimento com as atividades da ICH Agroecologia na escola:

1) Contato com as crianças e dinâmicas de interação;

2) Contato com a terra;

3) Inspiração para elaboração de Projetos de Aprendizagem;

4) Aproximação com a concepção de Agroecologia e seu papel no cotidiano;

5) Aproximação com temas específicos para dinâmicas com as crianças;

6) Amadurecimento de concepções no início do curso de graduação;

7) Responsabilidade no planejamento e nas ações e contato com as escolas;

8) Segurança e vivência nas ações com adultos e crianças.

9) Contribuição nas ações pedagógicas das escolas.

O trabalho entre universidade, centro de educação infantil, escola municipal e escola estadual foi potencializado pela articulação dos projetos em andamento, pelo respeito aos objetivos e ações desenvolvidas pelos diferentes atores sociais e pelo objetivo comum: a busca do desenvolvimento das crianças e a sensibilização para as questões ambientais. Acreditamos que um fator essencial para a continuidade e a concretização das ações foi a clara intenção nas reuniões de planejamento de que um projeto não deveria se sobrepor ao outro, dada a sua origem ou instituição, e, sim, que todos os envolvidos deveriam focar nos objetivos comuns, voltados ao desenvolvimento das crianças e sensibilização das questões ambientais, propiciando uma ação cooperativa e sinérgica entre os atores e respectivos projetos.

As figuras a seguir (Figuras 1,2,e 3) mostram as atividades desenvolvidas no CMEI Caminho Alegre, durante a aplicação do Projeto "Meio Ambiente, Escola e Família", que possibilitou a aproximação e a parceria entre extensionistas do curso da Agroecologia, professores, crianças e familiares.

A primeira atividade do Projeto "Meio Ambiente, Escola e Família", em parceria com monitores da ICH da UFPR, setor Litoral, consistiu no incentivo e na valorização do espaço do CMEI por meio da construção de um jardim em parceria com as famílias dos alunos, o que possibilitou a realização de atividades pedagógicas em educação ambiental já inseridas no currículo, o que auxiliou no processo de ensino-aprendizagem e estreitou as relações entre escola, família e comunidade por intermédio da promoção do trabalho coletivo. SCARDUA (2009) em seu artigo destaca que: "a união da Educação Ambiental e da Educação Infantil é primordial para criar uma nova geração que conheça e compreenda a natureza, tratando-a com respeito e admiração, reconhecendo-se como parte integrante dela". Assim a participação da criança foi fundamental ao longo de todo o processo e proporcionou a elas conhecimentos acerca dos diferentes tipos de solo e sementes, importância da água, do consumo consciente e das espécies de plantas da mata atlântica para, posteriormente, dar início ao plantio e cuidado do jardim. No que se refere à Educação Ambiental o RCNEI traz em seu terceiro volume 
"Natureza e Sociedade" as orientações para que o educador possa abordar o tema propondo caminhos para que:

(...) as crianças tenham contato com diferentes elementos, fenômenos e acontecimentos do mundo, sejam instigadas por questões significativas para observá-los e explicá-los e tenham acesso a modos variados e de compreendêlos e representá-los (BRASIL, 1998, p.166).

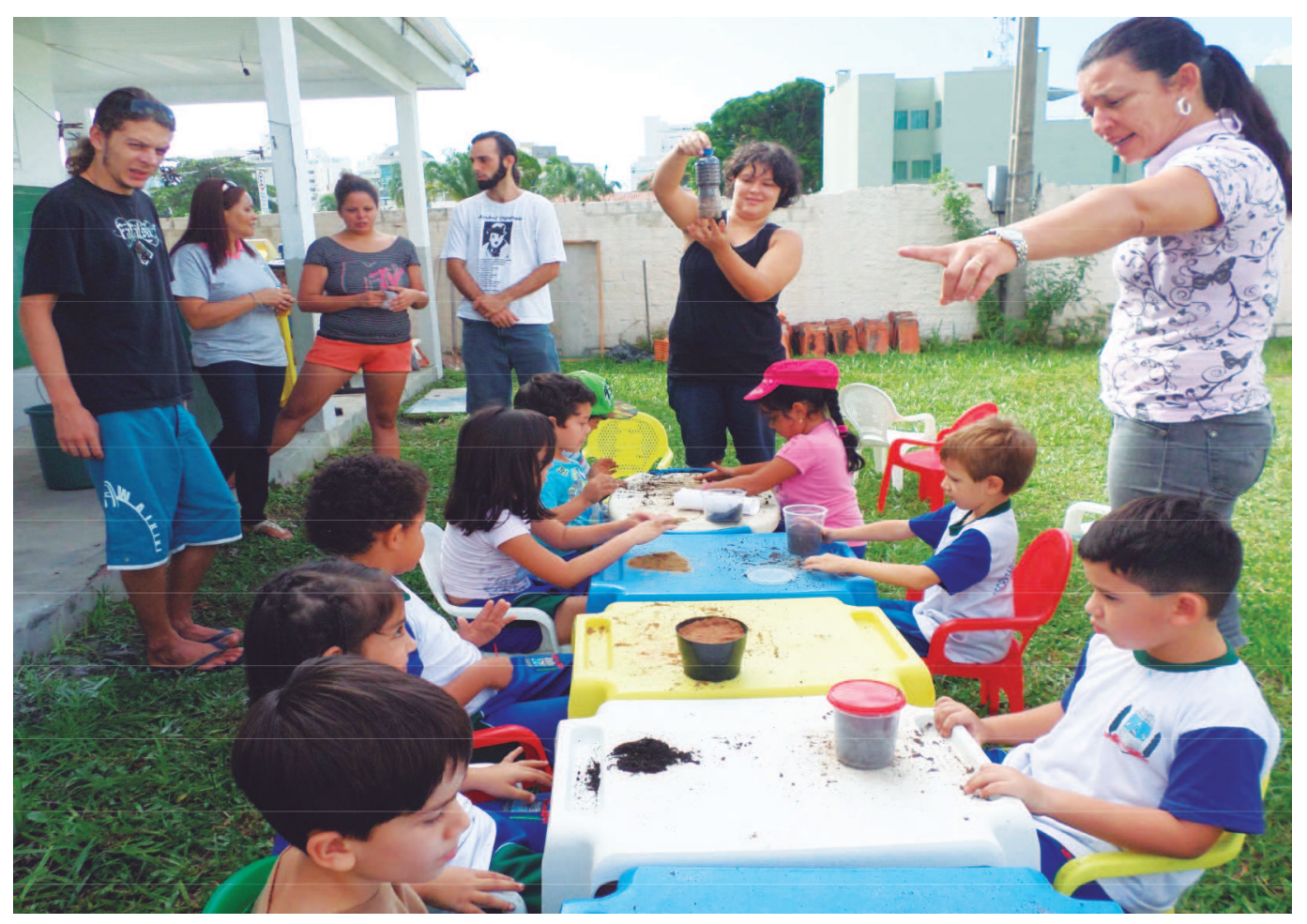

Figura 1- Estudo sobre os diferentes tipos de solos Fonte: CMEI Caminho Alegre- 2014

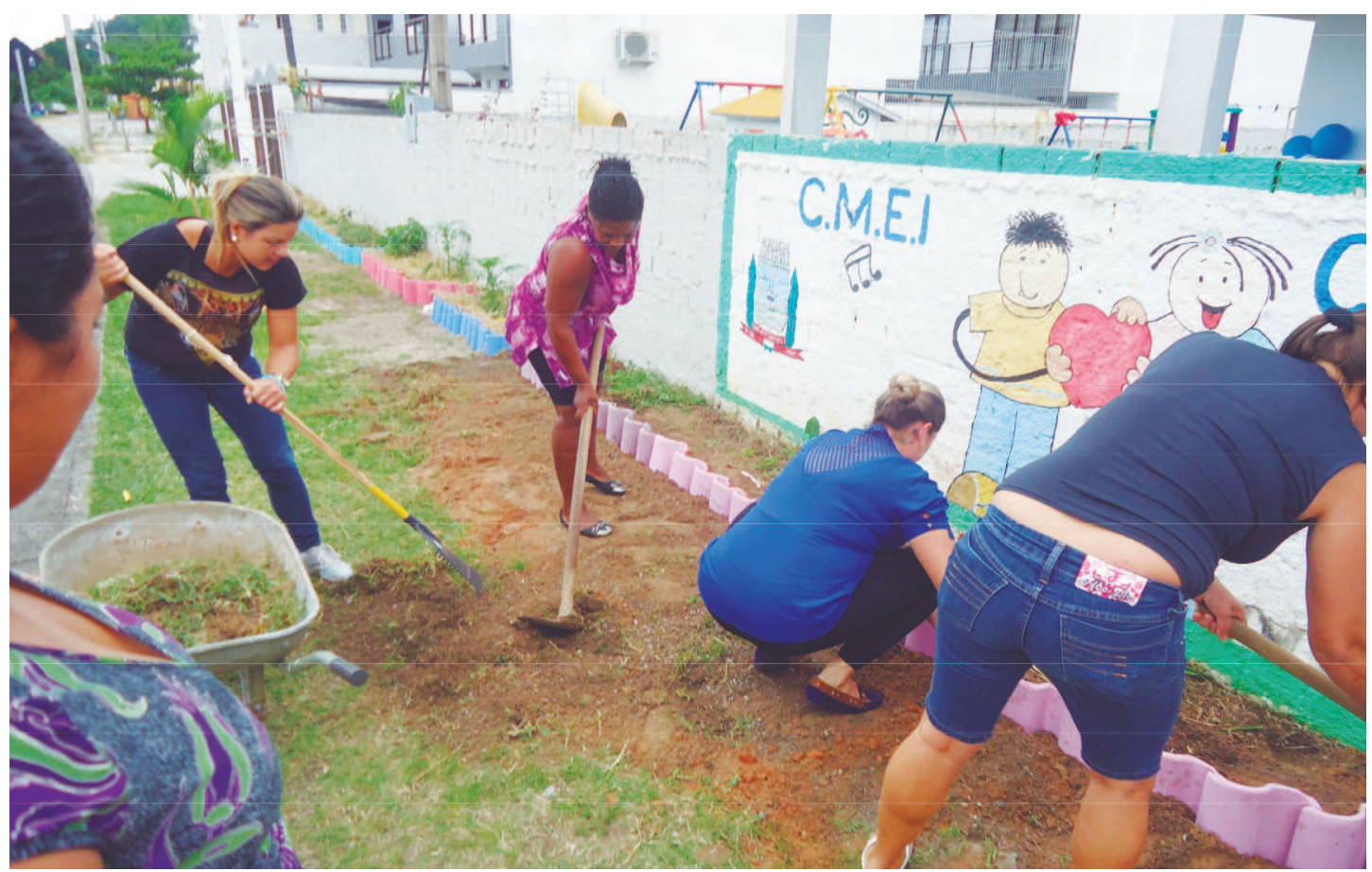

Figura 2- Reconstrução dos Canteiros

Fonte: CMEI Caminho Alegre- 2015 


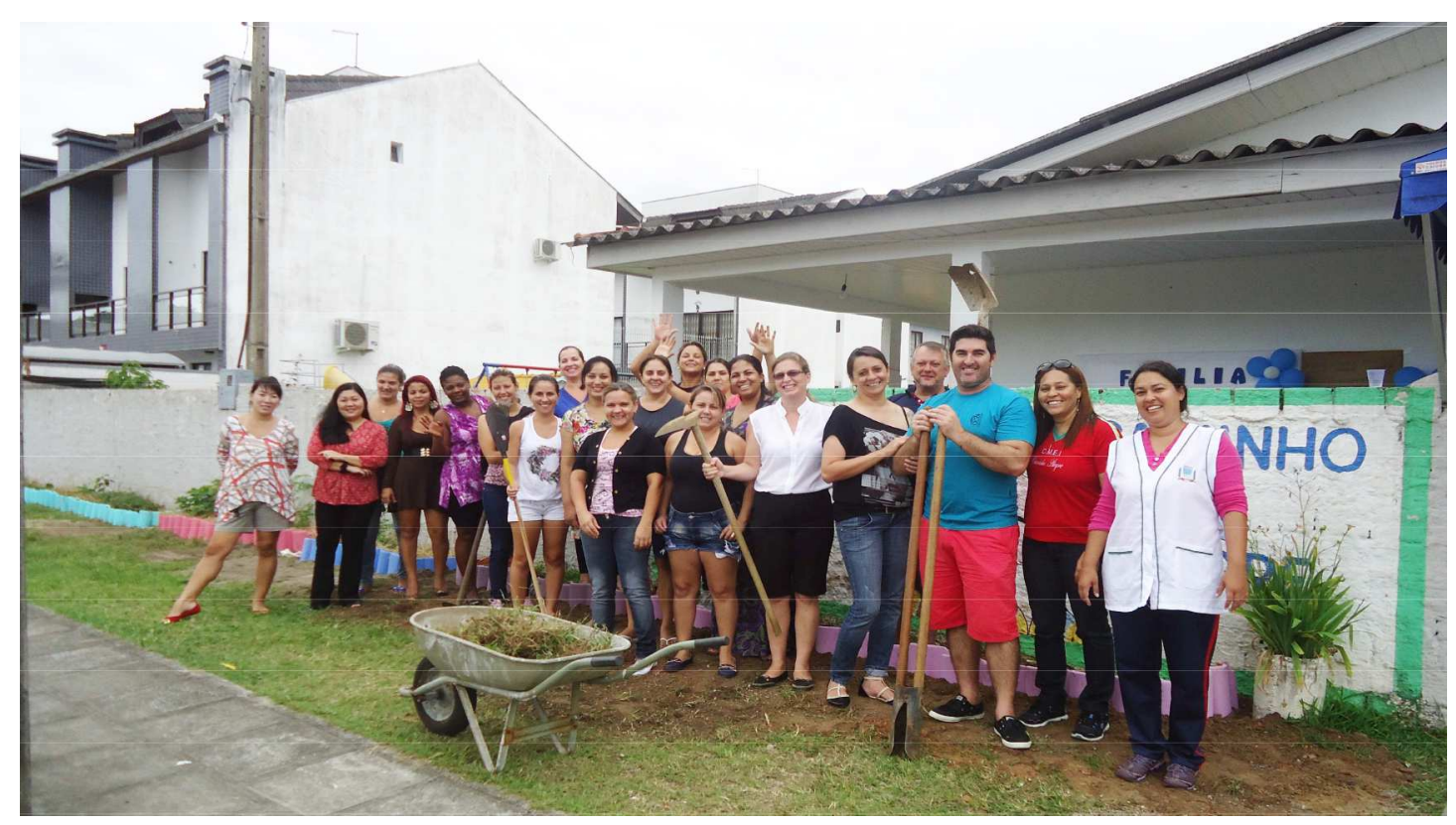

Figura 3- Resultado final da Reconstrução dos Jardins

Fonte: CMEI Caminho Alegre- 2015

Desta forma, a atividade foi aplicada em todas as turmas, incluindo Maternal II, Pré I e Pré II, com crianças de 0 a 05 anos no ano letivo de 2014, sendo os materiais utilizados trazidos pelas próprias crianças. $\mathrm{O}$ trabalho com os diversos tipos de solos, como areia, argila, terra preta e barro, possibilitou, além da vivência concreta, a confecção das tintas, a partir das orientações e explicações dos professores e monitores. O resultando dessa prática foi uma atividade rica e significativa para as crianças.

Uma outra atividade do "Projeto Meio Ambiente, Escola e Família" foi realizada no ano letivo de 2015 e foi aplicada no dia de um evento escolar denominado "Família na escola", o momento que reforçou a parceria existente entre família e escola por meio de atividades práticas nas quais todos contribuíram de alguma forma. Esse momento foi muito rico e contou com a participação dos familiares dos alunos na confecção de canteiros e com a participação dos alunos no plantio das sementes e das mudas de flores. $\mathrm{O}$ trabalho manual realizado pelos monitores da $\mathrm{ICH}$ consistiu na retirada de telhas, lavagem e pintura delas, revitalização do local, limpeza e retirada do mato, que já havia se instalado nos canteiros, e orientação das famílias e dos professores no dia do evento com a colocação das telhas e mistura da terra comum com a adubada. A Figura 3 mostra a participação na atividade de reconstrução dos canteiros no dia do Evento "Família na Escola", com os canteiros ao fundo já reconstruídos e prontos para serem utilizados em diversas atividades com as crianças.

\section{CONCLUSÃO}

A realização da atividade, sua sistematização e avaliação permitem concluir que a interação ensino superior e ensino infantil: 1) favorece a aprendizagem nos diferentes âmbitos de conhecimento, 2) enriquece a experiência educativa na indissociabilidade do ensino, pesquisa e extensão, e 3) possibilita o diálogo entre diferentes profissionais e níveis de ensino.

O envolvimento familiar e as atividades sensoriais potencializam o envolvimento e a percepção ambiental estreitando a relação com a natureza, consequentemente o respeito e a adoção de práticas ecológicas no cotidiano escolar. Simultaneamente, a relação com as crianças e as temáticas despertam nos universitários em formação a responsabilidade do conhecimento e o interesse por didáticas que permitam compartilhá-lo socialmente. Esse foi um gratificante trabalho, embora exigente em dedicação e compromisso que permitiu contribuir nas reflexões e práticas de educação ambiental.

Uma ação concreta de cunho interinstitucional em torno da temática ambiental em acordo com as demandas escolares foi para a equipe do projeto um grande desafio, as práticas aqui descritas são tentativas de superá-lo. É importante salientar que essa ação foi uma construção de aproximações e que as pessoas envolvidas, embora em instituições distintas em sua história e percursos de vida, aproximaram-se por afinidade em torno da temática ambiental anterior a elaboração do projeto. Tal aproximação potencializou as ações previstas e laços de confiança refletidos em ações executadas. Em 
outras iniciativas, deverá ser considerado, como um aspecto importante, os laços de compromisso com o tema e a afinidade das metodologias e práticas entre os indivíduos que atuam nas atividades do projeto.

\section{Agradecimento}

Gratidão à contribuição dos pares à versão preliminar do texto no âmbito do $2^{\circ}$ Congresso de Extensão da Associação de Universidades do Grupo de Montevidéu (AUGM), em outubro de 2015, na Universidade Estadual de Campinas, Campinas, São Paulo, Brasil.

\section{ÓRGÃO DE FINANCIAMENTO}

Pró-Reitoria de Extensão e Cultura - PROEC-UFPR (duas bolsas de extensão); Pró-Reitoria de Graduação (uma bolsa de monitoria); Setor Litoral-UFPR (materiais de consumo); famílias vinculadas à escola (materiais e voluntariado).

\section{Referências Bibliográficas}

BRASIL. Ministério da Educação. Secretaria da Educação Básica. Diretrizes curriculares nacionais para a educação infantil. Brasília: MEC-SEB, 2010a.

BRASIL. SEF. Ministério da Educação e Cultura. Referencial Curricular Nacional para a Educação Infantil. Brasília: MEC/SEF, 1998.

BRASIL. Legislação brasileira sobre meio ambiente: biodiversidade. Brasília: Câmara dos Deputados, Edições Câmara, 2010b.

SCARDUA, V.M. Crianças e Meio Ambiente: A importância da Educação Ambiental na Educação Infantil. Revista FACEVV, Vila Velha, n.3.p.57-64.2009.

Recebido para publicação em 28/4/2016 e aprovado em 27/6/2016. 